JoIE: Journal of Islamic Economics | Alliza Nur Shadrina, Muhammad Anwar Fathoni, Tati Handayani.

P-ISSN: 2807-7377

E-ISSN: 2807-7091

\title{
PENGARUH TRENDFASHION, GAYA HIDUP, DAN BRAND IMAGE TERHADAP PREFERENSI FASHION HIJAB
}

\author{
Alliza Nur Shadrina, Muhammad Anwar Fathoni, Tati Handayani \\ Universitas Pembangunan Nasional Veteran Jakarta, Indonesia \\ Institut Agama Islam Negeri Ponorogo, Indonesia \\ alliza.nur@upnvj.ac.id,mfathoni@upnvj.ac.id, tati.handayani@upnvj.ac.id
}

\begin{abstract}
Fashion is one of the most important daily needs of human beings. Dressing in addition to being a necessity can also reflect the way of life of a particular community as well as being an expression on one's personality as an identity identity then a variety of choices of clothing models each person can be influenced by different preferences. Everyone's preference for decision making on an item including dress style is influenced by many factors. This research aims to explain how fashion trends, lifestyle and brand image influence hijab fashion preferences. This research uses quantitative research method. The population used in this study is all Jabodetabek students who wear hijab. The data collection technique in this study used questionnaire method on 155 reponden. The variables used in this study consist of 2 independent variables and dependent variable. This study uses multiple linear regression data analysis techniques using SPSS 20 data processing program. The results given from this study show that the three variables' independents of trend fashion, lifestyle, and brand image have a significant influence on hijab fashion preferences. Lifestyle variables have the most dominant influence on hijab fashion preferences. So that the three variables of trend fashion, lifestyle, and brand image influence the increase of hijab fashion preference in an effort to develop the potential of the fashion hijab industry.
\end{abstract}

Keywords: Preferences, Brand Image, Fashion Trends, Lifestyle, Hijab

Abstrak: Fashion atau gaya berbusana termasuk salah satu kebutuhan sehari-hari manusia yang paling utama. Berpakaian selain menjadi kebutuhan juga dapat mencerminkan cara hidup kelompok masyarakat tertentu serta menjadi suatu ekspresi pada kepribadian seseorang sebagai identitas jati dirimaka beragam pilihan model pakaian setiap orang dapat dipengaruhi preferensi masing-masing yang berbeda. Preferensi setiap orang dalam pengambilan keputusan terhadap suatu barang termasuk gaya berpakaian dipengaruhi olehbanyak faktor. Penelitian ini bertujuan untuk menjelaskan bagaimana pengaruh trend fashion, gaya hidup dan brand image terhadap preferensi fashion hijab. Penelitian ini menggunakan metode penelitian kuantitatif. Populasi yang digunakan pada penelitian ini ialah seluruh mahasiswi Jabodetabek yang mengenakanhijab. Teknik pengumpulan data pada penelitian ini menggunakan metode kuesioner pada 155 reponden. Variabel yang digunakan di penelitian ini terdiri dari 2 yaitu variabel independen dan variabel dependen. Penelitian ini menggunakan teknik analisis data regresi liniear berganda dengan menggunakan program pengolah data SPSS 20. Hasil yang diberikan dari penelitian ini menunjukkan bahwa ketiga variabel bebas trend fashion, gaya hidup, dan brand image memiliki pengaruh yang signifikan terhadap preferensi fashion hijab. Variabel gaya hidup memiliki pengaruh paling dominan terhadap preferensi fashion hijab. Sehingga ketiga variabel trend fashion, gaya hidup, dan brand image mempengaruhi peningkatan preferensi fashion hijab dalam upaya mengembangkan potensi industri busana hijab. 
JoIE: Journal of Islamic Economics | Alliza Nur Shadrina, Muhammad Anwar Fathoni, Tati Handayani.

P-ISSN: 2807-7377

E-ISSN: 2807-7091

Kata Kunci: Preferensi, Brand Image, trend fashion, Gaya Hidup, Hijab

\section{PENDAHULUAN}

Wanita muslim sebagian besar sangat memperhatikan penampilan. Sektor halal selain makanan dan kosmetik juga masuk dalam ranah fashion atau gaya berpakaian, tidak sedikit perkembangan halal fashion ini menjadi tren fashion mainstream terutama bagi wanita muslim karena identitas yang membedakan antara wanita muslim dengan wanita non muslim yakni diantaranya jilbab. Wanita muslim beriringan dengan aturan gaya hidup ideal yang telah ditentukan dalam hukum islam. Laporan dari Global Islamic Economy Indicator (GIEI) 2019/2020 melaporkan bahwa Indonesia berada pada 15 besar negara dengan rata-rata konsumen pada bidang industri halal terbesar di dunia dan dalam laporan tersebut melaporkan bahwa Indonesia berada pada kategori Top 10 Modest Fashion di peringkat ke-3 (Standard, 2019).

Tabel 1. Laporan GIEI Top 10 Modest Fashion 2019/20

\begin{tabular}{cc}
\hline Rank & Negara \\
\hline 1 & United Arab Emirates \\
2 & Turkey \\
3 & Indonesia \\
4 & Malaysia \\
5 & Singapore \\
6 & Italy \\
7 & Bangladesh \\
8 & Morocco \\
9 & India \\
10 & Sri Lanka \\
\hline
\end{tabular}

Sumber: Data Diolah (2021)

Dari peringkat lima teratas, Indonesia bersaing dengan negara Uni Emirat Arab, Turki, Malaysia dan Singapura. Bisa dikatakan dari empat negara yang disebut hanya negara Singapura yang negaranya tidak memiliki warga mayoritas Muslim. Empat negara lainnya memiliki penduduk dengan mayoritas warga negara Muslim.

Indonesia sendiri dalam memanfaatkan potensi industri halal khususnya fashion muslim ini masih perlu kesiapan mulai dari pra-produksi, pemasaran hingga distribusi. Maka dari itu diperlukan peran dari berbagai pihak seperti perancang mode, pengusaha fashion 
JoIE: Journal of Islamic Economics | Alliza Nur Shadrina, Muhammad Anwar Fathoni, Tati Handayani.

P-ISSN: 2807-7377

E-ISSN: 2807-7091

muslim, produsen tekstil, pusat perbelanjaan, institusi pemerintah maupun swasta hingga media massa agar bersatu dalam menjalin komunikasi demi terwujudnya upaya yang nyata serta berkelanjutan (Ulfa, 2019). Indonesia memiliki potensi yang sangat besar dalam perkembangan industri halal karena jumlah penduduk muslim di Indonesia diperkirakan akan mencapai 256 juta jiwa hingga pada tahun 2050. Maka pertumbuhan industri halal khususnya sektor keuangan, wisata, dan fashion di Indonesia ini mulai dipandang oleh dunia, keadaan geografis Indonesia, kemajuan teknologi serta disahkannya UU Produk Jaminan Halal nomor 33 tahun 2014 hal ini membuka peluang potensi cukup besar bagi Indonesia dalam pengembangan industri halal (Fathoni \& Syahputri, 2020).

Pada beberapa tahun belakangan ini berkembang trend fashion muslimah di Indonesia, munculnya trend ini ditampilkan dengan beberapa beragam gaya busana hijab. Model yang sedang banyak diminati seperti blouse, kulot, rok tutu, hijab bella square, dan lain sebagainya. Jenis model fashion muslimah ini mudah untuk dipadu-padankan pada kesempatan apapun (Asmita \& Erianjoni, 2019). Didukung oleh peningkatan preferensi masyarakat sehingga tercipta keberagaman untuk memenuhi permintaan maka fashion muslimah seperti hijab mulai banyak berkembang karena sebagian masyarakat muslim kini mulai sadar untuk memilih produk yang memenuhi syariat islam (Faried, 2019). Pemilihan fashionhijab dapat dipengaruhi oleh preferensi masing-masing dengan selerayang berbeda, kemampuan atau lain sebagainya

Era modern sekarang ini, perkembangan trend gaya busana hijab berkembang pesat pada industri fashion hijab. Model dan tren baru terus dibuat di setiap musim yang akan mempengaruhi kesadaran mode dari konsumen yang selanjutnya akan menentukan tingkat konsumsi fashion hijab (Edastami \& Mahfudz, 2019). Preferensi konsumen yang berbedaberbeda terhadap desain fashion hijab yang mereka pilih untuk konsumsinya diikuti perkembangan trend gaya busana hijab, produsen terus menciptakan inovasi guna meningkatkan potensi daya saing di pasar.

Gaya hidup tidak terlepas dari hal gaya berbusana yang dimana mendukung untuk seseorang terus menerus mengikuti perubahan gaya busanayang ada agar menjadikan seseorang tersebut untuk selalu up-to-date terhadap fashion (Sukendro, Destiarman, \& Kahdar, 2016); (Genarsih, 2021). Gaya hidup ini menuntut seorang individu untuk selalu mengikuti perkembangan gaya busana saat ini sehingga membentuk preferensi yang cenderung memilih produk seiring perkembangan dari gaya busanamodifikasinya. 
JoIE: Journal of Islamic Economics | Alliza Nur Shadrina, Muhammad Anwar Fathoni, Tati Handayani.

P-ISSN: 2807-7377

E-ISSN: 2807-7091

Kini fashion hijab telah menjadi gaya hidup yang memberikan dampak positif maupun negatif dari fenomena perkembangan busana hijab saat ini. Adapun dampak positif yang diberikan dari busana hijab sebagai gaya hidup era modern sekarang yakni meningkatkan minat para wanita muslim untuk mengenakan hijab karena kesan model hijab masa kini yang lebih modern dan simpel. Namun terdapat dampak negatifnya ketika perkembangan hijab ini masih terdapat menyalahi aturan syariat islam tentang gaya berbusana (Mahmud, Paat, \& Lesawengen, 2020).

Brand image turut berperan dalam mempengaruhi hubungan antara keyakinan dan preferensi untuk pengambilan keputusan atas suatu produk yang dimana ketika produk tersebut memiliki citra positif akan lebih banyak menarik perhatian konsumen (Supriyadi, Fristin, \& KN, 2016). Citra dari merek yang dibangun oleh sebuah produk akan merubah penilaian dari konsumen yang dimana membentuk keyakinan pada suatu produk sehingga konsumen lebih menyukai produk tersebut. Bagi konsumen, brand image mencerminkan pengalaman dan pengetahuan mereka serta menyederhanakan pemrosesan informasi yang terkumpul dari waktu ke waktu tentang perusahaan dan produk atau mereknya. Selain itu, brand image mampu mencerminkan pengalaman dan pengetahuan konsumen sebagai preferensi (Amer, Jani, Ibrahim, \& Aziz, 2019).

Dari penelitian terdahulu terdapat kesenjangan penelitian diantaranya perbedaan hasil dari penelitian terdahulu yakni pada penelitian Rojoniaina (2018) apabila brand imageberpengaruh signifikan terhadap preferensi konsumen sedangkan dalam penelitian yang disusun oleh Wendy (2019) memberikan hasil dimanabrand image tidak berpengaruh signifikan terhadap preferensi konsumen. Adapun penelitian yang telah dilakukan oleh Eliaanti (2016) memberikan hasil apabila gaya hidup variabel minat memberikan hasil pengaruh signifikan terhadap preferensi. Selanjutnya penelitian yang dilakukan oleh Giacinta (2017) menghasilkan apabila gaya hidup variabel ketertarikan atau minat tidak memberikan hasil pengaruh signifikan terhadap preferensi. Kemudian masih sedikit penelitian yang menguji variabel trendfashion terhadap preferensi.

Dari penelitian sebelumnya membahas faktor yang mempengaruhi preferensi konsumen terdapat kekosongan yang dapat dilengkapi dalam penelitian ini, belum adanya penelitian yang menggunakan variabel gaya hidup secara spesifik terhadap preferensi fashion hijab dan brand image secara spesifik terhadap preferensi fashion hijab. Maka adapun novelty penelitian initerkait faktor-faktor yang mempengaruhi preferensi dalam fashion hijab 
JoIE: Journal of Islamic Economics | Alliza Nur Shadrina, Muhammad Anwar Fathoni, Tati Handayani.

P-ISSN: 2807-7377

E-ISSN: 2807-7091

yakni pengukuran variabel gaya hidup dan brand image terhadap preferensi fashion hijab.

Berdasarkan latar belakang yang telah dijabarkan, bahwa perkembangan fashion hijab di Indonesia yang belakangan ini telah membawa Indonesia pada peringkat ke-3 top modest fashion secara global berdasarkan laporan State of the Global of Islamic Economy 2019/2020. Hal ini diikuti dengan peningkatan preferensi yang dipengaruhi oleh beberapa faktor-faktor. Penelitian ini menggunakan variabel bebas diantaranya, trend fashion, gaya hidup, dan brand image karena dalam penelitian sebelumnya sejumlah variabel tersebut mempengaruhi preferensi. Maka tujuan penelitian ini adalah untuk menjelaskan pengaruh trend fashion, gaya hidup, dan brand image terhadap preferensi fashion hijab.

\section{TINJAUAN PUSTAKA}

\section{Preferensi}

Preferensi dapat diartikan ketika seseorang yang lebih cenderung menyukai akan sesuatu hal rata-rata daripada yang ekstrim, maka hal tersebut dapat termasuk ke dalam asumsi muatan ekonomis bernilai kecil (Karim, 2014). Preferensi merupakan suatu sikap subjektif independen untuk memilih sesuatu yang lebih disukai ketika membuat keputusan individu sesuai dengan kebutuhan-kebutuhan yang didasari dengan keinginan dan rasa suka (Hudri, 2020). Pengembangan produk erat kaitannya dengan manfaat yang ditawarkan dari suatu produk tersebut. Maka manfaat dari produk yang ditawarkan dapat disampaikan melalui atribut produk diantaranya (Kotler \& Armstrong, 2018):

a. Kualitas produk (product quality)

Kualitas produk ini adalah salah satu alat dalam upaya paling utama yang dilakukan oleh pemasar. Kualitas produk ini dapat mempengaruhi kinerja produk yang mana berkaitan erat dengan penilaian pelanggan dan kepuasan.

b. Fitur produk (product feature)

Fitur dari suatu produk merupakan alat bagi perusahaan untuk bersaing dan dapat dibedakan dengan produk pesaingnya. Upaya agar bisa meraih posisi sebagai produsen pertama yang memperkenalkan fitur baru dimana memiliki manfaat berharga maka hal ini adalah salah satu cara paling efektif untuk bersaing.

c. Desain dan tampilan (style and design)

Upaya lain yang dapat dilakukan guna menambah penilaian dari pelanggan yakni melalui perbedaan gaya dan desain produk. Desain sendiri memiliki konsep yang lebih 
JoIE: Journal of Islamic Economics | Alliza Nur Shadrina, Muhammad Anwar Fathoni, Tati Handayani.

P-ISSN: 2807-7377

E-ISSN: 2807-7091

luas dibandingkan gaya. Gaya hanya menjelaskan penampilan dari suatu produk. Desain dirancang untuk memberikan kontribusi dalam kegunaan produk serta penampilannya.

\section{Trend Fashion}

Trend fashion merupakan salah satu unit gaya hidup yang didorong oleh kemajuan teknologi dalam pertukaran referensi dari luar secara global. Pada zaman sekarang di Indonesia yang mengalami perkembangan modern terhadap fashion memiliki trend -nya sendiri dengan latar budaya yang kaya maka dihasilkan kreativitas pada trend fashion dengan sentuhan multikultural. Trend fashion di Indonesia juga dipengaruhi oleh nilai religius yang dimana penduduk Indonesia mayoritas muslim (Sari, 2018). Trend Fashion merupakan arah atau tendensi dimana akan lebih cenderung memilih suatu hal dalam mode contohnya seperti potongan, warna, gaya, dan lain sebagainya pada kurun waktu tertentu dimana trend mengalami perubahan dari waktu ke waktu (Hardisurya, Mardiana Pambudy, \& Herman, 2011).

Fashion adalah sebuah ungkapan yang ingin ditunjukkan oleh pemakainya dan lewat penampilan dapat menentukan seseorang mendapat perlakuan yang mereka inginkan. Islamic fashion memiliki arti lebih khusus dimana sebagai tata cara berbusana atau berpenampilan dengan memiliki norma batasan yang telah ditentukan (Jenahara \& Riamiranda, 2014).

Beraneka ragam fashion bermunculan dimana pada umumnya mengundang kontroversi di berbagai kalangan. Maka apabila ditinjau dari pandangan yang berbeda tiap masing-masing pandangan maka sebagai parameter atas konsep fashion diantaranya adalah (Ilyas, 2016):

a. Aurat

Keragaman fashion tidak menjadi masalah namun ketika digunakan dan ditampilkan oleh para perempuan lalu mengumbar aurat, ini yang menjadi masalah padahal seorang muslim sendiri telah diperintahkan untuk menutup aurat. Sesuai pada firman Allah SWT sebagai berikut:

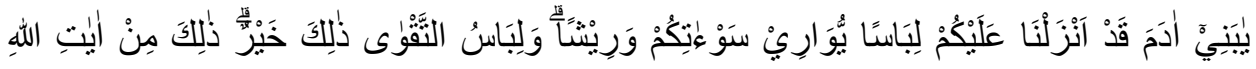

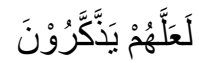

"Wahai anak cucu Adam, sungguh Kami telah menurunkan kepadamu pakaian untuk menutupi auratmu dan bulu (sebagai bahan pakaian untuk menghias diri). (Akan tetapi,) pakaian takwa itulah yang paling baik. Yang demikian itu merupakan sebagian tandatanda (kekuasaan) Allah agar mereka selalu ingat." (Qs. Al A'raf ayat 26) (Kementrian 
JoIE: Journal of Islamic Economics | Alliza Nur Shadrina, Muhammad Anwar Fathoni, Tati Handayani.

P-ISSN: 2807-7377

E-ISSN: 2807-7091

Agama Republik Indonesia, 2019).

b. Etika Bisnis

Berbagai usaha yang terkait dengan fashion merupakan hal yang menjanjikan karena dalam penjualannya cukup mudah dan peminatnya. Islam begitu menghargai usaha tiap manusia asalkan tetap berada di koridor islam

c. Tujuan Hukum Islam

Pada dasarnya untuk membangun kemaslahatan dunia dan akhirat. Apabila dalam mengenakan fashion memperlihatkan aurat maka ini bertentangan maka dalam pemilihan fashion harus memperhatikan aspek kemaslahatan.

d. Dampak Sosial

Kemunculan trend fashion dapat menciptakan karya dari desainer muslimah hal ini merupakan sisi positifnya akan tetapi juga ada sisi negatifnya yakni bisa menimbulkan sikap hedonis dan konsumerisme.

Pernyataan ini juga didukung dengan penelitian terdahulu trend fashion mempengaruhi konsumen dalam kecenderungannya memilih produk fashion (Ayunda, Mutmainah, \& Huda, 2019). Adapun trend fashion berpengaruh signifikan dalam mempengaruhi pemilihan fashion hijab mahasiswi(Rania, 2018).

Maka berdasarkan teori dan penelitian terdahulu di atas terkait pengaruh trend fashion terhadap preferensi dapat dirumuskan hipotesis sebagai berikut:

H1: Trend fashion berpengaruh signifikan terhadap preferensi fashion hijab.

\section{Gaya Hidup}

Gaya hidup memiliki definisi yakni sebagai pola hidup yang dapat diungkapkan melalui aktivitas, minat, dan juga opini seseorang. Bagaimana setiap individu berinteraksi dengan lingkungannya dapat memperlihatkan keseluruhan pribadi orang tersebut dari gaya hidup. Secara kasat mata dengan pola gaya hidup karakter seseorang dapat dinilai melalui sikap kepada dirinya sendiri serta lingkungan sekitarnya (Kotler \& Keller, 2016).

Terdapat beberapa faktor yang mempengaruhi gaya hidup seorang individu diantaranya berikut ini (Priansa, 2017):

a. Faktor internal

1) Sikap

Sikap adalah keadaan jiwa yang membuat refleksi dari wawasan dan pola pikir 
JoIE: Journal of Islamic Economics | Alliza Nur Shadrina, Muhammad Anwar Fathoni, Tati Handayani.

P-ISSN: 2807-7377

E-ISSN: 2807-7091

konsumen ketika memberikan tanggapan terhadap suatu objek berdasarkan pengalaman.

2) Pengalaman dan pengamatan

Pengamatan sosial dalam perilaku individu ini dapat dipengaruhi oleh pengalaman.

Pengamatan ini dapat diperoleh melalui bagaimana perbuatan dan perilaku individu di masa lalu.

3) Kepribadian

Cara berperilaku setiap masing-masing individu yang membedakannya satu sama lain karena karakter mereka yang berbeda-beda.

4) Konsep diri

Pola kepribadian memiliki inti yakni konsep diri hal ini yang menentukan sebuah perilaku individu ketika dihadapi permasalahan hidup.

5) Motif

Adanya perilaku individu muncul berasal dari sebuah motif dalam pemenuhan kebutuhannya.

6) Persepsi

Proses yang dilakukan individu dalam proses pemilihan, penyesuaian dan menginterpretasikan informasi yang mereka dapatkan.

b. Faktor eksternal

1) Kelompok referensi

Kelompok yang memberikan pengaruh secara langsung atau tidak langsung terhadap perilaku dan sikap dari individu.

2) Keluarga

Peran yang paling besar dipegang oleh keluarga ini karena pola asuh yang diberikan orang tua akan membentuk perilaku anaknya dimana hal ini tentunya akan mempengaruhi gaya hidup anak.

3) Kelas Sosial

Sekumpulan orang yang dimana terdapat susunan urutan dari anggotanya yang memiliki nilai, minat, dan tingkah laku yang sama.

4) Kebudayaan

Kebudayaan terdiri dari pengetahuan, keyakinan, kesenian, akhlak moral, hukum serta adat dan kebiasaan yang didapati konsumen sebagai individu tergabung dalam 
JoIE: Journal of Islamic Economics | Alliza Nur Shadrina, Muhammad Anwar Fathoni, Tati Handayani.

P-ISSN: 2807-7377

E-ISSN: 2807-7091

masyarakat.

Pernyataan ini juga didukung dengan penelitian terdahulu Gaya hidup indikator minat dan opini berpengaruh signifikan terhadap preferensi (Christine, 2016). Namun adapun penelitian menghasilkan bahwa gaya hidup indikator aktivitas dan opini berpengaruh signifikan terhadap preferensi (Palupi, 2017).

Maka berdasarkan teori dan penelitian terdahulu di atas terkait pengaruh trend fashion terhadap preferensi dapat dirumuskan hipotesis sebagai berikut:

H2: Gaya hidup berpengaruh signifikan terhadap preferensi fashion hijab.

\section{Brand Image}

Citra merek atau brand image mewakilkan keseluruhan persepsi merek yang dibentuk oleh informasi merek serta pengalaman yang pernah dialami sebelumnya. Citra merek juga berkaitan dengan keyakinan dan sikap terhadap preferensi merek. Konsumen dengan keyakinan citra merek positif lebih cenderung akan melakukan keputusan pembelian. Citra merek memiliki makna sebagai suatu yang dipikirkan dan dirasakan konsumen ketika mendengar atau melihat nama merek (Firmansyah, 2018).

Menurut Biel citra dari suatu merek dapat dijabarkan sebagai tiga komponen yang diantaranya (Biel \& Aaker, 2013):

a. Corporate Image (Citra Perusahaan)

Dalam hal ini citra perusahaan meliputi: popularitas dan kredibilitas. Citra yang dimiliki oleh perusahaan mempunyai pengaruh yang besar terhadap pengambilan keputusan oleh konsumen.

b. User Image (Citra Pemakai)

Dalam hal ini citra pemakai meliputi sebagai berikut gaya hidup serta kepribadian pengguna dan status sosial. Citra pemakai erat kaitannya dengan kepribadian, kebanyakan konsumen memilih suatu produk.

c. Product Image (Citra Produk)

Citra produk ini meliputi atribut produk, kegunaan bagi konsumen, pelayanan serta jaminan kualitas.

Pernyataan ini juga didukung dengan penelitian terdahuludimanabrand image memiliki pengaruh signifikan terhadap preferensi konsumen (Capistran, 2018). Adapun penelitian lain menyatakan hasil brand image tidak memiliki pengaruh signifikan terhadap preferensi 
JoIE: Journal of Islamic Economics | Alliza Nur Shadrina, Muhammad Anwar Fathoni, Tati Handayani.

P-ISSN: 2807-7377

E-ISSN: 2807-7091

konsumen (Calvind, 2019).

Maka berdasarkan teori dan penelitian terdahulu di atas terkait pengaruh trend fashion terhadap preferensi dapat dirumuskan hipotesis sebagai berikut:

H3: Brand image berpengaruh signifikan terhadap preferensi fashion hijab.

\section{METODOLOGI PENELITIAN}

Penelitian ini menggunakan metode penelitian kuantitatif. Penelitian ini memiliki populasi mahasiswi Jabodetabek dengan jumlah populasi belum diketahui. Pada penelitian ini dilakukan pengambilan sampel menggunakan teknik non probability sampling dengan purposive sampling. Sampel penelitian ini memiliki kriteria reponden yakni mahasiswi domisili Jabodetabek dan mengenakanhijab. Penetapan jumlah sampel yang berdasarkan dari teknik pengambilan populasi dimana masih belum diketahui menggunakan rumus Lemeshow (Riyanto \& Hatmawan, 2020). Ketentuan rumus tersebut mengumpulkan data sekurangkurangnya dari 100 responden. Penelitian ini menggunakan 155 responden sesuai kriteria.

Penelitian ini menggunakan sumber data primer. Dimana data dari penelitian yang dilakukan ini diperoleh melalui penyebaran kuesioner ke seluruh mahasiswi yang berhijab di wilayah Jabodetabek.Jenis kuesioner pada penelitian ini ialah kuesioner tertutup yang telah disediakan jawabannya (Siregar, 2013). Skala yang digunakan dalam teknik pengukuran data ini ialah skala likert model skala empat dimana pada model ini tidak memberikan peluang responden untuk menjawab netral sehingga membuat responden menentukan sikap lebih tegas terhadap fenomena pada setiap pernyataan instrumen.

Rangkaian instrumen dapat digunakan untuk mengukur variabel ini, sehingga sejumlah data dapat dilakukan analisis dengan prosedur statistik. Setelah melakukan pengumpulan data maka penulis mulai mengelompokkan data sesuai dengan variabel dari masing-masing responden. Kemudian melakukan perhitungan melalui analisis deskriptif untuk menjawab pertanyaan yang telah dirumuskan. Analisis data dilakukan guna untuk menguji hipotesis dan mengetahui pengaruh dari variabel independen $(\mathrm{X} 1, \mathrm{X} 2$, dan $\mathrm{X} 3)$ terhadap variabel dependen (Y). Adapun penelitian ini menggunakan program SPSS20 dalam melakukan analisis data. Untuk analisis instrumen maka dilakukan beberapa pengujian yaitu uji validitas dan uji reliabilitas. Selanjutnya, uji asumsi klasik, uji regresi, uji hipotesis dan uji koefisien determinasi. 
JoIE: Journal of Islamic Economics | Alliza Nur Shadrina, Muhammad Anwar Fathoni, Tati Handayani.

P-ISSN: 2807-7377

E-ISSN: 2807-7091

\section{HASIL DAN PEMBAHASAN}

\section{Deskripsi Data Penelitian}

Pada analisis data deskriptif langkah untuk mengumpulkan data berbentuk angka berbentuk catatan kemudian data berbentuk angka tersebut diolah dalam bentuk grafik untuk dilakukan analisis dan ditafsirkan yang nantinya akan menghasilkan sebuah kesimpulan (Silvia, 2020).

1. Karakteristik Responden Berdasarkan Usia

Berikut adalah data responden berdasarkan karakteristik usia:

Tabel 2. Responden Berdasarkan Usia

\begin{tabular}{llll}
\hline No. & Usia & Frekuensi & Presentase \\
\hline 1 & $17-23$ tahun & 149 orang & $96,1 \%$ \\
2 & $24-39$ tahun & 6 orang & $3,9 \%$ \\
& Jumlah & 155 orang & $100 \%$ \\
\hline
\end{tabular}

Sumber: Data diolah (2021)

Diperoleh nilai dari data yang telah diolah pada tabel maka dapat disimpulkan bahwa kategori usia 17 - 23 tahun paling banyak mendominasi sebesar 96,1\% dari jumlah responden.

2. Karakteristik Responden Berdasarkan Domisili Tempat Tinggal

Berikut adalah data responden berdasarkan karakteristik domisili tempat tinggal:

Tabel 3. Responden Berdasarkan Domisili Tempat Tinggal

\begin{tabular}{cccc}
\hline No. & Usia & Frekuensi & Presentase \\
\hline 1 & Jakarta & 53 orang & $34,2 \%$ \\
2 & Bogor & 18 orang & $11,6 \%$ \\
3 & Depok & 20 orang & $12,9 \%$ \\
4 & Tangerang & 17 orang & $11,0 \%$ \\
5 & Bekasi & 47 orang & $30,3 \%$ \\
& Jumlah & 155 orang & $100 \%$ \\
\hline
\end{tabular}

Sumber: Data diolah (2021)

Diperoleh nilai dari data yang telah diolah pada tabel maka dapat disimpulkan bahwa kategori berdomisili Jakarta paling banyak mendominasi sebesar 34,2\% dari jumlah responden. 
JoIE: Journal of Islamic Economics | Alliza Nur Shadrina, Muhammad Anwar Fathoni, Tati Handayani.

P-ISSN: 2807-7377

E-ISSN: 2807-7091

3. Karakteristik Responden Berdasarkan Pendidikan Saat Ini

Berikut adalah data responden berdasarkan karakteristik pendidikan saat ini:

Tabel 4. Responden Berdasarkan Pendidikan Saat Ini

\begin{tabular}{cccc}
\hline No. & Usia & Frekuensi & Presentase \\
\hline 1 & Diploma & 15 orang & $9,7 \%$ \\
2 & S1 & 135 orang & $87,1 \%$ \\
3 & S2 & 5 orang & $3,2 \%$ \\
& Jumlah & 155 orang & $100 \%$ \\
\hline
\end{tabular}

Sumber: Data diolah (2021)

Diperoleh nilai dari data yang telah diolah pada tabel maka dapat disimpulkan bahwa kategori jenjang pendidikan S1 paling banyak mendominasi sebesar 87,1\% dari jumlah responden.

4. Karakteristik Responden Berdasarkan Pendapatan/Uang Saku Per-bulan

Berikut adalah data responden berdasarkan karakteristik pendapatan/uang saku perbulan:

Tabel 5. Responden Berdasarkan Pendapatan/Uang Saku Per-bulan

\begin{tabular}{cccc}
\hline No. & Usia & Frekuensi & Presentase \\
\hline 1 & $<$ Rp. 500.000 & 49 orang & $31,8 \%$ \\
2 & Rp. 500.000 - Rp. 1.999.999 & 81 orang & $51,9 \%$ \\
3 & Rp. 2.000.000 - Rp. 3.999.999 & 16 orang & $10,4 \%$ \\
4 & Rp. 4.000.000 - Rp. 5.000.000 & 2 orang & $1,3 \%$ \\
5 & $>$ Rp. 5.000.000 & 7 orang & $4,5 \%$ \\
& Jumlah & 155 orang & $100 \%$ \\
\hline
\end{tabular}

Sumber: Data diolah (2021)

Diperoleh nilai dari data yang telah diolah pada tabel maka dapat disimpulkan bahwa pendapatan/uang saku Rp. 500.000 - Rp. 1.999.999 paling banyak mendominasi sebesar 51,9\% dari jumlah responden.

\section{Uji Instrumen}

\section{Uji Validitas}

Ketentuan pada uji validitas yakni apabila $r_{\text {hitung }}>r_{\text {tabel }}$ kuesioner tersebut valid. Namun apabila $r_{\text {hitung }}<r_{\text {tabel }}$ kuesioner tersebut tidak valid. 
JoIE: Journal of Islamic Economics | Alliza Nur Shadrina, Muhammad Anwar Fathoni, Tati Handayani.

P-ISSN: 2807-7377

E-ISSN: 2807-7091

a. Uji Validitas Preferensi (Y)

Berikut tabel hasil dari uji validitas pada variabel preferensi (Y) dengan 5 pernyataan.

Tabel 6. Uji Validitas Preferensi (Y)

\begin{tabular}{cccc}
\hline Pernyataan & R hitung & R Tabel & Kriteria \\
\hline Pernyataan 1 & 0,696 & 0,344 & Valid \\
Pernyataan 2 & 0,415 & 0,344 & Valid \\
Pernyataan 3 & 0,686 & 0,344 & Valid \\
Pernyataan 4 & 0,788 & 0,344 & Valid \\
Pernyataan 5 & 0,558 & 0,344 & Valid \\
\hline
\end{tabular}

Sumber: Data diolah (2021)

Pada tabel uji validitas semua nilai $r$ hitung $>r$ tabel maka kesimpulannya dari 5 pernyataan indikator variabel preferensi ialah valid dan dapatdilanjutkan dalam model pengujian.

b. Uji Validitas Trend Fashion (X1)

Berikut tabel hasil dari uji validitas pada variabel trend fashion (X1) dengan 4 pernyataan.

Tabel 7. Uji Validitas Trend Fashion (X1)

\begin{tabular}{cccc}
\hline Pernyataan & R hitung & R Tabel & Kriteria \\
\hline Pernyataan 1 & 0,769 & 0,344 & Valid \\
Pernyataan 2 & 0,749 & 0,344 & Valid \\
Pernyataan 3 & 0,701 & 0,344 & Valid \\
Pernyataan 4 & 0,675 & 0,344 & Valid \\
\hline
\end{tabular}

Sumber: Data diolah (2021)

Pada tabel uji validitas semua nilai $r$ hitung $>r$ tabel maka kesimpulannya dari 4 pernyataan indikator variable trend fashion ialah valid dan dapat dilanjutkan dalam model pengujian.

c. Uji Validitas Gaya Hidup (X2)

Berikut tabel hasil dari uji validitas pada variabel gaya hidup (X2) dengan 5 pernyataan. 
JoIE: Journal of Islamic Economics | Alliza Nur Shadrina, Muhammad Anwar Fathoni, Tati Handayani.

P-ISSN: 2807-7377

E-ISSN: 2807-7091

Tabel 8. Uji Validitas Gaya Hidup (X2)

\begin{tabular}{cccc}
\hline Pernyataan & R hitung & R Tabel & Kriteria \\
\hline Pernyataan 1 & 0,378 & 0,344 & Valid \\
Pernyataan 2 & 0,63 & 0,344 & Valid \\
Pernyataan 3 & 0,786 & 0,344 & Valid \\
Pernyataan 4 & 0,756 & 0,344 & Valid \\
Pernyataan 5 & 0,605 & 0,344 & Valid \\
\hline
\end{tabular}

Sumber: Data diolah (2021)

Pada tabel uji validitas semua nilai $r$ hitung $>\mathrm{r}$ tabel maka kesimpulannyadari 5 pernyataan indikator variabelgaya hidupialah valid dan dapat dilanjutkan dalam model pengujian.

\section{d. Uji Validitas Brand Image (X3)}

Berikut tabel hasil dari uji validitas pada variabel brand image (X3) dengan 5 pernyataan.

Tabel 9. Uji Validitas Brand Image (X3)

\begin{tabular}{cccc}
\hline Pernyataan & R hitung & R Tabel & Kriteria \\
\hline Pernyataan 1 & 0,587 & 0,344 & Valid \\
Pernyataan 2 & 0,576 & 0,344 & Valid \\
Pernyataan 3 & 0,800 & 0,344 & Valid \\
Pernyataan 4 & 0,849 & 0,344 & Valid \\
Pernyataan 5 & 0,799 & 0,344 & Valid \\
\hline
\end{tabular}

Sumber: Data diolah (2021)

Pada tabel uji validitas semua nilai $\mathrm{r}$ hitung > r tabel maka kesimpulannyadari 5 pernyataan indikator variable brand image ialah valid dan dapat dilanjutkan dalam model pengujian.

\section{Uji Realiabilitas}

Uji reliabilitas memiliki ketentuan apabila taraf alpha terhitung $>0,60$ alat ukur memiliki reliabilitas tinggi. Apabila nilai dari perhitungan uji reabilitas $=0,60$ berarti nilai tersebut adalah reliabilitas, jika perhitungan uji reliabilitas bernilai $<0,60$ berarti nilai tersebut tidak reliabilitas. 
JoIE: Journal of Islamic Economics | Alliza Nur Shadrina, Muhammad Anwar Fathoni, Tati Handayani.

P-ISSN: 2807-7377

E-ISSN: 2807-7091

Tabel 10. Uji Reliabilitas

\begin{tabular}{cccc}
\hline Variabel & Cronbach Alpha & Nilai Kritis & Kriteria \\
\hline Preferensi & 0,630 & 0,60 & Reliabel \\
Trend Halal Fashion & 0,688 & 0,60 & Reliabel \\
Gaya Hidup & 0,619 & 0,60 & Reliabel \\
Brand Image & 0,736 & 0,60 & Reliabel \\
\hline
\end{tabular}

Sumber: Data diolah (2021)

Diperoleh data dari tabel yakni seluruh variabel dalam penelitian ini preferensi, trend halal fashion, gaya hidup, dan brand image menunjukkan hasil Cronbach alpha > 0,60. Maka kesimpulannya adalah pernyataan yang dipakai penelitian ini reliabel oleh karena itu dapat digunakan untuk penelitian selanjutnya.

\section{Uji Asumsi Klasik}

\section{Uji Normalitas}

Uji normalitas dilakukan agar diketahui bahwa nilai residual penelitian ini layak dan baik digunakan pada umumnya data tersebut berdistribusi normal. Uji normalitas ini dapat dihitung dengan Kolmogrov-Smirnov Test di SPSS.

Tabel 11. Uji Normalitas

\begin{tabular}{cc}
\hline $\mathbf{N}$ & Signifikasi \\
\hline 155 & 0,700 \\
\hline
\end{tabular}

Sumber: Data Diolah (2021)

Berdasarkan pada tabel Kolmogrov-Smirnov Test di atas menunjukkan nilai Asymp. Sig. sebesar $0,700>0,05$. Sesuai dengan hasil tabel tersebut maka dapat ditarik kesimpulan bahwa data telah berdistribusi normal. Jadi, persyaratan normalitas dalam model regresi penelitian ini telah terpenuhi.

\section{Uji Multikolinearitas}

Pada uji ini dilihat dari nilai tolerance dan inflantion. 
JoIE: Journal of Islamic Economics | Alliza Nur Shadrina, Muhammad Anwar Fathoni, Tati Handayani.

P-ISSN: 2807-7377

E-ISSN: 2807-7091

Tabel 12. Uji Multikolinearitas

\begin{tabular}{ccc}
\hline Variabel & Tolerance & VIF \\
\hline Trend Fashion & 0,631 & 1,585 \\
Gaya Hidup & 0,640 & 1,562 \\
Brand Image & 0,688 & 1,453 \\
\hline
\end{tabular}

Sumber: Data diolah (2021)

Nilai tolerance untuk variabel Trend Halal Fashion (X1) adalah 0,631> 10 nilai tolerance variabel Gaya Hidup (X2) adalah 0,640 > 0,10 nilai tolerance variabel Brand Image (X3) adalah 0,688 > 0,10. Nilai VIF variabel Trend Fashion (X1) adalah 1,585 < 10,00 nilai VIF Gaya Hidup (X2) adalah 1,562 < 10,00 nilai VIF Brand Image (X3) adalah $1,453<10,00$. Berdasarkan dari tabel di atas menunjukkan bahwa tidak terjadi Multikolinearitas dalam model regresi.

\section{Uji Heteroskedastisitas}

Model pengujian ini dilakukan untuk pembuktian bahwa varian residual tidak memiliki kesamaan di setiap pengamatan model regresi. Pengujian ini dapat dilakukan dengan metode grafik scatterplot dan juga korelasi spearman's rho.

Gambar 1. Scatterplot

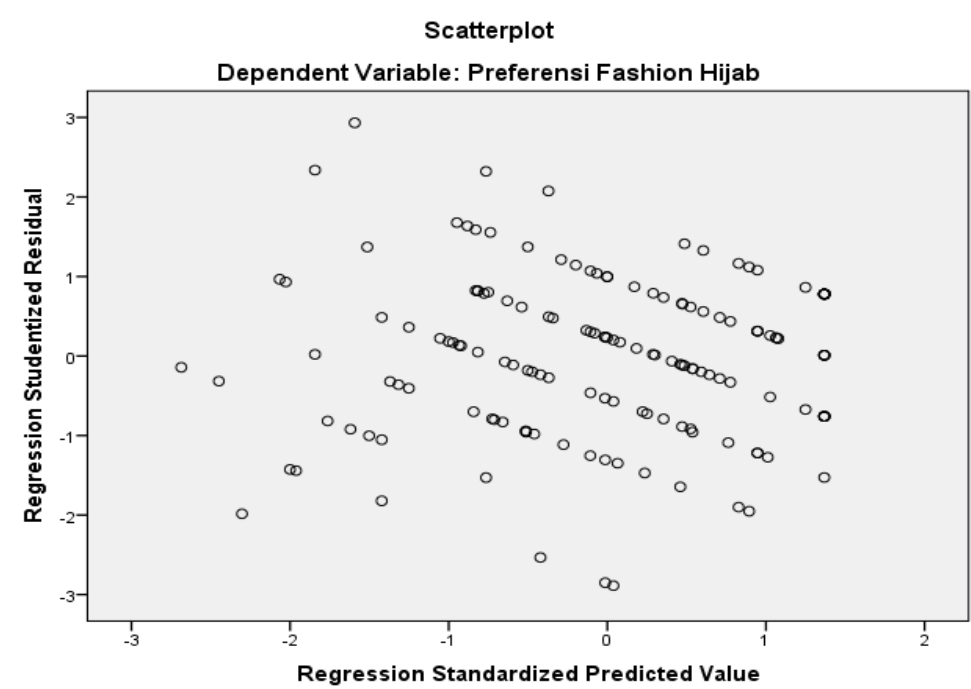

Sumber: Data diolah (2021)

Berdasarkan gambar grafik di atas dari data yang diolah menunjukkan pola yang terbentuk tidak beraturan menyebar pada sumbu Y di bawah dan di atas angka 0 maka tidak terjadi heteroskedastisitas dalam model regresi. 
JoIE: Journal of Islamic Economics | Alliza Nur Shadrina, Muhammad Anwar Fathoni, Tati Handayani.

P-ISSN: 2807-7377

E-ISSN: 2807-7091

Tabel 13. Korelasi Spearman's Rho

\begin{tabular}{cc}
\hline Variabel & Signifikasi \\
\hline Trend Fashion & 0,763 \\
Gaya Hidup & 0,773 \\
Brand Image & 0,584 \\
\hline
\end{tabular}

Sumber: Data Diolah (2021)

Berdasarkan tabel spearman's rho di atas nilai Sig. trend halal fashion (X1) sebesar $0,736>0,05$ nilai Sig. gaya hidup (X2) sebesar $0,773>0,05$ nilai Sig. brand image sebesar 0,584 >0,05. Dengan demikian, dapat ditarik kesimpulan bahwa data tidak terjadi problem heteroskedastiditas karena nilai signifikan yang didapatkan lebih besar dari 0,05.

\section{Uji Hipotesis}

\section{Uji t}

Dalam penelitian iniuji hipotesis secara parsial akan menggunakan uji-t dengan pengambilan pemutusan apabila nilai $t_{\text {hitung }}>t_{\text {tabel }}$ menunjukkan bahwaa hipotesis yang diajukan dapat diterima.

Tabel 14. Hasil Uji t

\begin{tabular}{cccc}
\hline Variabel & t-hitung & t-tabel & Sig. \\
\hline Trend Fashion & 2,118 & 1,654 & 0,036 \\
Gaya Hidup & 4,399 & 1,654 & 0,000 \\
Brand Image & 2,016 & 1,654 & 0,046 \\
\hline
\end{tabular}

Sumber: Data diolah (2021)

\section{a. Pengaruh variabel trend fashion (X1) terhadap preferensi fashion hijab}

Berdasarkan hasil dari tabel di atas, nilai Sig. untuk pengaruh trend fashion terhadap preferensi fashion hijabdiperoleh sebesar 0,036 $<0,05$ adapun nilai thitung sebesar 2,118 > 1,654. Maka dari itu dapat ditarik kesimpulan apabilaadanya pengaruh yang signifikan dari variabel trend fashion (X1) terhadap variabel preferensi (Y), dapat dikatakan juga bahwa hipotesis Ho ditolak dan Ha diterima.

Maka hasil uji ini sejalan dengan penelitian yang telah dilakukan (Rania, 2018) bahwa trend busana muslimah berpengaruh signifikan terhadap gaya busana muslimah mahasiswi. 
JoIE: Journal of Islamic Economics | Alliza Nur Shadrina, Muhammad Anwar Fathoni, Tati Handayani.

P-ISSN: 2807-7377

E-ISSN: 2807-7091

\section{b. Pengaruh variabel gaya hidup (X2) terhadap preferensi fashion hijab}

Berdasarkan hasil dari tabel di atas, nilai Sig. untuk pengaruh gaya hidup terhadap preferensi fashion hijabdiperoleh sebesar $0,000<0,05$ adapun nilai thitung sebesar 4,399 $>$ 1,654. Maka dari itu dapat ditarik kesimpulan apabila adanya pengaruh yang signifikan dari variabel gaya hidup (X1) terhadap variabel preferensi (Y), dapat dikatakan juga bahwa hipotesis Ho ditolak dan Ha diterima.

Maka hasil uji ini sejalan dengan penelitian yang telah dilakukan. penelitian yang telah dilakukan (Palupi, 2017) menghasilkan bahwa gaya hidup indikator aktivitas dan opini berpengaruh signifikan terhadap preferensi. Adapun (Christine, 2016) gaya hidup indikator minat dan opini berpengaruh signifikan terhadap preferensi.

\section{c. Pengaruh variabel brand image (X3) terhadap preferensi fashion hijab}

Berdasarkan hasildari tabel diatas, nilai Sig. untuk pengaruh brand image terhadap preferensifashion hijab diperoleh sebesar 0,046 $<0,05$ adapun nilai $t_{\text {hitung }}$ sebesar 2,016> 1,654. Maka dari itu dapat ditarik kesimpulan apabilaadanya pengaruh yang signifikan dari variabelbrand image (X1) terhadap variabel preferensi (Y), dapat dikatakan juga bahwa hipotesis Ho ditolak dan Ha diterima.

Maka hasil uji ini sejalan dengan penelitian yang telah dilakukan. penelitian yang telah dilakukan (Capistran, 2018) menghasilkan bahwa brand image berpengaruh signifikan terhadap preferensi konsumen.

\section{Uji F (Simultan)}

Pengujian secara keseluruhan dilakukan guna mengetahui adanya pengaruh secara bersamaanpada variabel $\mathrm{X}$ terhadap variabel $\mathrm{Y}$. Pengujian ini dilakukan dengan menggunakan distribusi $\mathrm{F}$ yakni melakukan perbandingan antara nila $\mathrm{F}_{\text {hitung }}$ dengan nilai $\mathrm{F}_{\text {tabel. }}$

Tabel 15. Hasil Uji F (Simultan)

\begin{tabular}{ccc}
\hline F-hitung & F-tabel & Sig \\
\hline 26,221 & 2,66 & 0,000 \\
\hline
\end{tabular}

Sumber: Data diolah (2021)

Diperoleh sebesarnilai sig. 0,000 $<0,05$ menunjukkan hasil yakni ketiga dari variabel trend fashion, gaya hidup, dan brand image memiliki pengaruh secara simultan atau

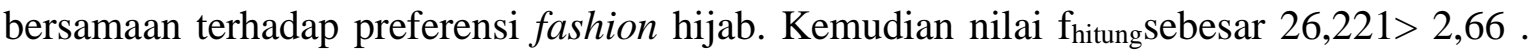


JoIE: Journal of Islamic Economics | Alliza Nur Shadrina, Muhammad Anwar Fathoni, Tati Handayani.

P-ISSN: 2807-7377

E-ISSN: 2807-7091

Maka dari itu disimpulkan bahwa adanya pengaruh dari variabel bebas $\mathrm{X} 1, \mathrm{X} 2$, dan X3 secara bersama atausimultan serta signifikan terhadap variabel dependen (Y), sehingga dapat ditarik kesimpulan dimana hipotesis Ho ditolak dan Hadapat diterima.

\section{Uji Koefisien Determinasi}

Pengujian ini dilakukan guna mengukur kemampuan dari model yang digunakan dalam menjelaskan variasi dari variabel dependen atau terikat. Berikut ini merupakan hasil dari uji koefisien determinasi.

Tabel 16. Hasil Uji Koefisien Determinasi

\begin{tabular}{cc}
\hline $\mathbf{R}$ & Adjusted $\mathbf{R}$ Square \\
\hline 0,585 & 0,329 \\
\hline
\end{tabular}

Sumber: Data Diolah (2021)

Diperoleh nilai dari datatabelyakniAdjusted $R$ Square (koefisien determinasi) yang dihasilkan adalah 0,329atau 32,9\% . Maka ditarik kesimpulan bahwa dari nilai Adjusted $R$ Square tersebut yakni sebesar 0,329 maka hasil tersebutmembuktikan kemampuan dari variabel bebas trend halal fashion, gaya hidup, dan brand image dalam menjelaskan preferensi fashion hijab sebesar 32,9 \% dan sisanya memiliki nilai sebesar $67,1 \%$ dipengaruhi oleh faktorlain yang tidak dibahas pada penelitian ini.

Dalam penelitian yang dilakukan oleh (Rania, 2018)pengaruh dari variabel trend busana muslimah terhadap gaya busana mahasiswi sebesar $34,02 \%$. Selain itu, penelitian yang telah dilakukan oleh (Palupi, 2017)nilai dari pengaruh gaya hidup terhadap preferensi memiliki adalah sebesar 14,9\%. Kemudian pada penelitian yang telah dilakukan oleh (Capistran, 2018) bahwa brand image dalam mempengaruhi preferensi memiliki nilai sebesar $61,8 \%$.

Berikut adalah tabel hasil dari perhitungan sumbangan efektif (SE) yang diolah menggunakan Excel. 
JoIE: Journal of Islamic Economics | Alliza Nur Shadrina, Muhammad Anwar Fathoni, Tati Handayani.

P-ISSN: 2807-7377

E-ISSN: 2807-7091

Tabel 17. Sumbangan Efektif (SE)

\begin{tabular}{cc}
\hline SE & Nilai \\
\hline $\mathrm{X} 1$ & 8,0 \\
$\mathrm{X} 2$ & 19,5 \\
$\mathrm{X} 3$ & 6,8 \\
$R$ Square & 34,3 \\
\hline
\end{tabular}

Sumber: Data Diolah (2021)

Tabel di atas menunjukan hasil sumbangan efektif (SE) bahwa variabel gaya hidup (X2) memiliki pengaruh yang mendominasi terhadap preferensi fashion hijab daripada variabel trend halal fashion dan brand image. Total sumbangan efektif yang diperoleh adalah sebesar 34,3\% yang dimana total SE sama dengan nilai $\mathrm{R}$ square.

Berikut adalah tabel hasil dari perhitungan sumbangan relatif (SR) yang diolah menggunakan Excel.

Tabel 18. Sumbangan Relatif (SR)

\begin{tabular}{cc}
\hline SR & Nilai \\
\hline $\mathrm{X} 1$ & 23,3 \\
$\mathrm{X} 2$ & 56,8 \\
$\mathrm{X} 3$ & 19,8 \\
$R$ Square & 100 \\
\hline
\end{tabular}

Sumber: Data Diolah (2021)

Tabel di atas menunjukan hasil sumbangan relatif (SR) bahwa sumbangan relatif (SR) gaya hidup (X2) terhadap preferensi fashion hijab (Y) paling mendominasi diantara variabel lainnya adalah sebesar 56,8\%.Total sumbangan relatif (SR) yang diperoleh adalah sebesar $100 \%$ atau sama dengan 1.

\section{Model Regresi Linear Berganda}

Analisis ini digunakan untuk mencari pengaruh antara variabel bebas yang berjumlah lebih dari satu terhadap variabel terikat. Berikut hasil uji dari regresi linear berganda.

Tabel 19. Hasil Uji Regresi linier Berganda

\begin{tabular}{ccc}
\hline No & Model & Koefisien Regresi \\
\hline 1 & Konstanta & 8,511 \\
2 & Trend fashion & 0,160
\end{tabular}


JoIE: Journal of Islamic Economics | Alliza Nur Shadrina, Muhammad Anwar Fathoni, Tati Handayani.

P-ISSN: 2807-7377

E-ISSN: 2807-7091

\begin{tabular}{ccc}
\hline No & Model & Koefisien Regresi \\
\hline 3 & Gaya hidup & 0,284 \\
4 & Brand image & 0,111 \\
\hline
\end{tabular}

Sumber: Data Diolah (2021)

Berdasarkan dari tabel regresi maka dapat dirumuskan persamaan regresi berganda ialah sebagai berikut: $\mathrm{Y}=8,511+0,160 \mathrm{X} 1+0,284 \mathrm{X} 2+0,111 \mathrm{X} 3+\mathrm{e}$.

Maka dapat ditarik kesimpulan dari persamaan regresi berganda tersebut di atas diantaranya sebagai berikut:

1. Nilai konstanta sebesar 8,511 memiliki arti bahwa variabel independen trend halalfashion, gaya hidup, dan brand imagememiliki nilai di atas 0 maka jumlah nilai preferensi fashion hijabjadi meningkat sebesar 8,511.

2. Nilai koefisien $X 1$ sejumlah 0,160 jadi setiap terjadi penambahan $1 \%$ dari nilai trend halal fashion meningkatkan tingkat preferensi terhadap fashion hijab sebesar 0,160. Nilai dari koefisien X1 ini menunjukkan hasil nilai positif. Maka dapat disimpulkan bahwa pengaruh variabel trend halal fashion (X1) terhadap variabel preferensi fashion hijab (Y) adalah positif.

3. Nilai koefisien X2 sejumlah 0,284 jadi setiap terjadi penambahan $1 \%$ dari nilai gaya hidup meningkatkan tingkat preferensi terhadap fashion hijab sebesar 0,160. Nilai dari koefisien X2 ini menunjukkan hasil nilai positif. Maka dapat disimpulkan bahwa pengaruh variabel gaya hidup(X2) terhadap variabel preferensi fashion hijab (Y) adalah positif.

Nilai koefisien X3 sejumlah 0,111 jadi setiap terjadi penambahan 1\% dari nilai brand image meningkatkan tingkat preferensi terhadap fashion hijab sebesar 0,111 . Nilai dari koefisien X3 ini menunjukkan hasil nilai positif. Maka ditarikkesimpulan yaitu pengaruh variabel brand image (X3) terhadap variabel preferensi fashion hijab (Y) adalah positif.

\section{KESIMPULAN}

Berdasarkan pembahasan dan hasil analisis yang peneliti uraikan sebelumnya mengenai analisis preferensi fashion hijab maka dapat ditarik kesimpulan ialah trend fashion, gaya hidup, dan brand imagememiliki pengaruh yang signifikan secara parsial dan simultan terhadap preferensi fashion hijab. Faktor yang ada pada ketiga variabel bebas ini dapat mempengaruhi preferensi dalam pemilihan busana hijab. Maka dapat disimpulkan 
JoIE: Journal of Islamic Economics | Alliza Nur Shadrina, Muhammad Anwar Fathoni, Tati Handayani.

P-ISSN: 2807-7377

E-ISSN: 2807-7091

perkembangan industri halal di Indonesia khususnya busana hijab ini berkembang sangat baik pada pelaku bisnis serta UMKM bidang busana hijab yang dimana dapat terwujud dengan memperhatikan trend fashion, gaya hidup, dan brand image dalam memenuhi preferensi para konsumen guna mengembangkan kualitas dan produksi busana hijab mereka menjadi lebih baik.

Penelitian ini memiliki keterbatasan penelitian diantaranya, masih sedikitnya sejumlah referensi dari penelitian terdahulu mengenai variabel trend fashion, gaya hidup, dan brand image di dalam satu penelitian secara keseluruhan. Adapun keterbatasannya penentuan sampel yang hanya pada lingkup mahasiswi Jabodetabek dan pengumpulan data dengan kuesioner dimanateknik pengumpulan data ini belum tentu menunjukkan pendapat responden yang sebenar-benarnya.

Berdasarkan dari hasil penelitian yang telah dilakukan maka penulis dapat merekomendasi untuk penelitian selanjutnya yaitu, dapat mengganti atau menambah variabel independen lain terkait preferensi fashion hijab seperti harga, promosi ataupun celebrity endorser guna untuk melengkapi penelitian yang sudah ada. Selain itu, dapat menggunakan sampel yang berbeda selain mahasiswi Jabodetabek. Diharapkan dari perbedaan ini dapat menyempurnakan lagi penelitian selanjutnya serta menghasilkan data yang lebih baik juga. Kemudian untuk pelaku bisnis dan UMKM untukmemerhatikan kembali produk hijab nya yang dapat sesuai pada aktivitas, minat dan opini atau pandangan konsumen terhadap produk hijab. Adapun memerhatikan aspek produk, perusahaan, dan pengguna dalam hal ini dilakukan demi menjaga brand image produk hijab yang dibangun serta tercipta citra yang mana pada benak konsumen itu menjadi lebih berkesan.Perkembangan trend fashion hijab di Indonesia juga berpengaruh dalam pemilihan gaya busana tiap muslimah namun trend fashion kebanyakan sekarang lebih condong kebarat-baratan dimana lebih mementingkan keindahan. Diharapkan setiap muslimah dalam mengenakan hijab tetap perhatikan dan sesuai dengan batasan aurat yang telah ditentukan.

\section{REFERENSI}

Amer, A., Jani, M. S. H., Ibrahim, I., \& Aziz, N. A. A. (2019). Brand preferences in Muslimah fashion industries: an insight of framework development and research implications. Humanities \& Social Sciences Reviews, 7(1).

Asmita, D., \& Erianjoni. (2019). Perilaku Konsumtif Mahasiswi dalam Mengikuti Trend FashionMasa Kini(Studi Kasus Mahasiswi Sosiologi FIS UNP). 2(2), 91-96. 
JoIE: Journal of Islamic Economics | Alliza Nur Shadrina, Muhammad Anwar Fathoni, Tati Handayani.

P-ISSN: 2807-7377

E-ISSN: 2807-7091

Ayunda, A., Mutmainah, L., \& Huda, N. (2019). Analisis Terhadap Perilaku Konsumen Produk Fashion Muslim. JEBA (Journal of Economics and Business Aseanomics), 3(2). https://doi.org/10.33476/jeba.v3i2.962

Biel, A., \& Aaker, D. (2013). Brand Equity and Advertising: Advertising's Role Building Strong Brands. Michigan: Psychology Press.

Calvind, W. (2019). Faktor yang Mempengaruhi Preferensi Konsumen antara Hotel Independen dan Hotel Chain di Kota Batam. Universitas Internasional Batam.

Capistran, R. P. (2018). Pengaruh Brand Image Terhadap Customer Preference Pada Brodo Footwear. Universitas Padjajaran.

Christine, E. (2016). Pengaruh Gaya hidup dan Demografi terhadap Preferensi Belanja Konsumen di Pasar Beringharjo. Universitas Atma Jaya Yogyakarta.

Edastami, M., \& Mahfudz, A. A. (2019). An Analysis of The Effect of Fashion Consciousness as A Mediating Factor on Hijab Fashion Consumption in Indonesia. Tazkia Islamic Finance and Business Review, 13(1).

Faried, A. I. (2019). Implementasi Model Pengembangan Industri Halal Fashion Di Indonesia. Jurnal Kajian Ekonomi Dan Kebijakan Publik, 4(2), 9-19.

Fathoni, M. A., \& Syahputri, T. H. (2020). Potret Industri Halal Indonesia: Peluang dan Tantangan. Jurnal Ilmiah Ekonomi Islam, 6(03), 428-435.

Firmansyah, A. (2018). Perilaku Konsumen (Sikap dan Pemasaran). Surabaya: TS Publisher.

Genarsih, T. (2021). Pengaruh Tingkat Pendapatan dan Jumlah Anggota Keluarga Terhadap Konsumsi Gas Elpiji Pada Sektor Rumah Tangga. JoIE: Journal of Islamic Economics, 1(1).

Hardisurya, I., Mardiana Pambudy, N., \& Herman, J. (2011). Kamus mode Indonesia (1st ed.). Jakarta: Gramedia Pustaka Utama.

Hudri, A. (2020). Badai Politik Uang dalam Demokrasi Lokal. Malang: Inteligensia Media.

Ilyas, M. (2016). Memaknai Fashion dalam Hukum Islam. 5.

Jenahara, \& Riamiranda. (2014). Fashion Friendship. Jakarta: Qultum Media.

Karim, A. A. (2014). Ekonomi Mikro Islam. Jakarta: PT. Rajawali Pers.

Kotler, P., \& Armstrong, G. (2018). Principles of Marketing (17th ed.). Harlow: Pearson Education Limited.

Kotler, P., \& Keller, K. L. (2016). Marketing Management (15th ed.). Harlow: Pearson Education.

Mahmud, Y., Paat, C. J., \& Lesawengen, L. (2020). Jilbab Sebagai Gaya Hidup Wanita Modern di Kalangan Mahasiswi Fakultas Ilmu Sosial dan Politik Universitas Sam Ratulangi. Holistik, 13(3), 1-14.

Palupi, G. R. (2017). Pengaruh gaya Hidup terhadap Preferensi Belanja Konsumen pada Kawasan Wisata Kotagede Yogyakarta. Sanata Dharma Yogyakarta. 
JoIE: Journal of Islamic Economics | Alliza Nur Shadrina, Muhammad Anwar Fathoni, Tati Handayani.

P-ISSN: 2807-7377

E-ISSN: 2807-7091

Priansa. (2017). Perilaku Konsumen dalam Persaingan Bisnis Kontemporar. Bandung: Alfabeta.

Rania, L. (2018). Pengaruh Trend Busana Muslimah terhadap Gaya Busana Kuliah Muslimah Mahsiswa Jurusan Manajemen Fakultas Ekonomi Universitas Negeri Yogyakarta. Universitas Negeri Yogyakarta.

Riyanto, S., \& Hatmawan, A. A. (2020). Metode Riset Penelitian Kuantitatif Penelitian Di Bidang Manajemen, Teknik, Pendidikan dan Eksperimen (1st ed.). Yogyakarta: Deepublish.

Silvia, V. (2020). Statistika Deskriptif (1st ed.). Yogyakarta: Andi.

Siregar, I. S. (2013). Metode Pemilihan Kuantitatif: Dilengkapi dengan Perbandingan Perhitungan Manual \& SPSS. Jakarta: KENCANA.

Standard, D. (2019). State of the Global Islamic Economy Report 2019/20. Dubai International Financial Centre, 1-174. Retrieved from https://haladinar.io/hdn/doc/report2018.pdf

Sukendro, G., Destiarman, A. H., \& Kahdar, K. (2016). Nilai fetisisme komoditas gaya hijab (kerudung dan jilbab) dalam busana muslimah. Jurnal Sosioteknologi, 15(2).

Supriyadi, Fristin, Y., \& KN, I. G. (2016). Pengaruh Kualitas Produk dan Brand Image Terhadap Keputusan Pembelian (Studi pada Mahasiswa Pengguna Produk Sepatu Merek Converse di Fisip Universitas Merdeka Malang). Bisnis Dan Manajemen, 3(1).

Ulfa, R. S. (2019). Upaya Ifc (Indonesian Fashion Chamber) Dalam Mewujudkan Indonesia Sebagai “the Fashion Muslim Center of the World 2025.” Jom Fisip, 6, 1-15. 